\title{
Midterm results of endovascular treatment of iliac artery lesions: analysis of 59 cases
}

\author{
Resultados a médio prazo do tratamento endovascular \\ das lesões de artérias ilíacas: análise de série de 59 casos*
}

Leonardo Ghizoni Bez',2

\begin{abstract}
Background: Endovascular treatment of peripheral arterial occlusive disease has become increasingly frequent in the past few years. Because it is a less invasive procedure, lower morbidity and mortality rates are associated with this form of treatment. Objectives: To describe the endovascular procedures performed in iliac arteries for the treatment of peripheral arterial occlusive disease. Methods: This retrospective study assesses 59 cases of iliac artery angioplasty performed according to a specific protocol from January 2004 to February 2010. Results: Mean age of patients was 62 years (minimum: 42, maximum: 89). Thirty seven were male (62.72\%) and 22 female (37.28\%). The main indications for treatment were moderate to severe intermittent claudication in 30 cases (50.84\%) and rest pain or trophic lesions (critical ischemia) in 29 cases (49.15\%). Postoperative follow-up included ankle-brachial index measurements and a duplex ultrasound at 30 days, 3 months, 6 months, 12 months, and every 6 months thereafter. Minimum follow-up time was 3 months, and maximum, 72 months ( 6 years), with primary and secondary patency rates of 91.37 and $94.82 \%$, respectively. Conclusions: The results of this case series, combined with literature review results, allow to conclude that the endovascular approach is an effective and safe option to treat peripheral arterial occlusive disease in iliac arteries.
\end{abstract}

Keywords: peripheral arterial disease; angioplasty; iliac artery; atherosclerosis.

\begin{abstract}
Resumo
Contexto: $O$ tratamento da doença arterial oclusiva periférica por via endovascular vem apresentando aumento progressivo nos últimos anos. Por se tratar de procedimento pouco invasivo, possui a vantagem de propiciar menos morbimortalidade. Objetivos: $O$ presente trabalho tem como objetivo verificar as intervenções endovasculares no território das artérias ilíacas para doença arterial oclusiva periférica. Métodos: Trata-se de estudo retrospectivo, avaliando, através de protocolo específico de coleta de dados, 59 casos de angioplastias de artérias ilíacas realizadas no período de janeiro de 2004 a fevereiro de 2010. Resultados: A idade média dos pacientes foi de 62 anos (mínima: 42, máxima: 89), sendo 37 do sexo masculino (62,72\%) e 22 do sexo feminino (37,28\%). As principais indicações para tratamento foram a claudicação intermitente limitante ou incapacitante em 30 casos (50,84\%) e a manifestação de dor em repouso ou lesão trófica (isquemia crítica) em 29 casos (49,15\%). Acompanharam-se os pacientes no pósoperatório, com medidas do índice tornozelo-braço e duplex-scan, aos 30 dias, três meses, seis meses, 12 meses e, posteriormente, de seis em seis meses. O seguimento mínimo foi de três meses e o máximo de 72 meses (seis anos), com perviedade primária de 91,37\% e secundária de 94,82\%. Conclusões: Os resultados desta série de casos e a revisão da literatura permitiram concluir que a abordagem endovascular é uma opção eficaz e segura para o tratamento da doença arterial oclusiva periférica no território das artérias ilíacas.
\end{abstract}

Palavras-chave: doença arterial periférica; angioplastia; artéria ilíaca; aterosclerose.

${ }^{1}$ Hospital Felício Rocho, Belo Horizonte, Belo Horizonte, MG, Brazil.

${ }^{2}$ Service of Vascular Surgery, Hospital do Instituto de Previdência dos Servidores do Estado de Minas Gerais - IPSEMG, Belo Horizonte, MG, Brazil. Financial support: None.

Conflicts of interest: No conflicts of interest declared concerning the publication of this article.

Submitted on: 03.11.11. Accepted on: 03.05.13

The study was carried out at Hospital Felício Rocho, Belo Horizonte, Minas Gerais, Brazil.

The study was carried out at Hospital do Instituto de Previdência dos Servidores do Estado de Minas Gerais -IPSEMG, Belo Horizonte, MG, Brazil.

*The study is part of a monograph presented by the author at Sociedade Brasileira de Angiologia e Cirurgia Vascular in order to become a full member with the society. 


\section{INTRODUCTION}

Peripheral arterial occlusive disease is responsible for thousands of amputations in Brazil every year. In the United States, about 100,000 amputations a year are due to lower extremity atherosclerosis ${ }^{1}$.

Chronic ischemia of lower limbs secondary to peripheral atherosclerotic disease may lead to intermittent claudication or critical ischemia, whose symptoms include rest pain and trophic lesion. Incidence increases with population age, as well as with risk factors, such as smoking, diabetes and hypercholesterolemia.

Patients with chronic lower limb ischemia have not only a high risk of limb amputation, but also higher morbidity and mortality rates due to ischemic heart and cerebrovascular diseases. Critical ischemia, which includes rest pain and tissue loss, is associated with an annual mortality rate of about $20 \%{ }^{2,3}$. Seldinger, in 1953, Dotter, in 1964, Grutzing, in 1974, and Palmaz, in 1985, were the pioneers of minimally invasive procedures in vascular surgery. Since their time, new devices, such as guide wires, catheters, balloons and stents, have been developed for endovascular interventions every year ${ }^{4-7}$.

The development of endovascular techniques to treat peripheral arterial diseases has enabled the use of minimally invasive methods and reduced morbidity and mortality in comparison with the rates obtained with conventional surgery.

In the region of the iliac artery, endovascular treatment has been associated with low morbidity and mortality when compared with open surgery. Procedures are performed under local anesthesia and percutaneously, which results in less surgical trauma to patients with multiple comorbidities. Patient recovery is rapid, and patency rates in the long term are comparable to those of open surgery.

\section{OBJECTIVE}

This study described and evaluated the results of a series of patients that underwent iliac artery angioplasty, as well as mid and long term results according to the following factors:

- primary patency rates;

- secondary patency rates;

- mortality rates;

- complications associated with procedure;

- amputation rates.

\section{METHOD}

From January 2004 to February 2010, 59 patients underwent endovascular interventions in the iliac artery. Data were collected retrospectively using a specific protocol presented to patients at the time of hospitalization. The protocol included data about patient age and sex, clinical severity of arterial disease (claudication, rest pain or tissue lesion), comorbidities and risk factors of atherosclerosis (smoking, diabetes, hypertension, dyslipidemia), laboratory tests and diagnostic procedures and vascular assessment. All patients signed an informed consent term at the time of hospitalization and granted permission for the performance of procedures. The consent term was the one used in the hospital where the patients underwent operation, approved by the Ethics Committee of the institutions where the study was conducted.

The patients underwent operations in two tertiary hospitals: a private hospital with 400 beds and a cardiovascular service; and a public hospital with 500 beds and a Residence Program in Vascular Surgery and a C-arm in the operating room for the performance of vascular interventions.

The procedures were performed under local anesthesia and sedation; the patients were hospitalized after angioplasty and discharged in the next morning. Antiplatelet therapy with $200 \mathrm{mg} /$ day of acetylsalicylic acid (AAS) and $75 \mathrm{mg} /$ day of clopidogrel was initiated three to five days before the intervention. The use of $75 \mathrm{mg} /$ day of clopidogrel was continued for 30 days after the operation, combined with $200 \mathrm{mg} /$ day of AAS. After 30 days, clopidogrel was discontinued, but AAS at $200 \mathrm{mg} /$ day was maintained.

All 59 patients underwent postoperative followup, which included clinical examinations, anklebrachial index measurements and a duplex ultrasound or CT angiogram at 30 days, 3 months, 6 months, 12 months, and every 6 months thereafter. Follow-up was performed by the author in the outpatient service of the public hospital and in his private office in the case of his private patients.

The protocol for data collection is shown in the supplementary annex (Annex 1).

\section{Description of angioplasty technique}

\section{Vascular access}

Access to the iliac artery was via retrograde ipsilateral puncture of the common femoral artery. Two techniques can be used for this puncture: puncture of the anterior wall of the artery only, using an arterial puncture needle; or use of a piercing technique and a Jelco $16 \mathrm{G}$ catheter. 
In patients without a femoral pulse, techniques for puncturing without a pulse were adopted, always using a puncture needle ${ }^{8}$ :

- radioscopy to identify the site at the intersection of the mid third and the medial third of the femur head;

- duplex scan guided puncture;

- injection for road-mapping from contralateral access;

- directions using previous angiograms;

- visualization of calcifications in the artery;

- lateral orientation to guide wire placed in the femoral vein.

In cases of ostial lesions of the common iliac artery, the bilateral puncture of femoral arteries was necessary to avoid the occlusion of the contralateral iliac artery by displacement of plaques from the bifurcation when the kissing balloon technique was used.

\section{Interventions in the aortic bifurcation}

This technique was used in cases of bilateral ostial lesions of the common iliac arteries. The technique had the following steps':

- retrograde right femoral puncture:

- placement of 6F or 7F introducer;

- retrograde left femoral punctures;

- placement of 6F or 7F introducer;

- arteriogram;

- road mapping;

- placement of 260-cm standard or stiff hydrophilic guide wires bilaterally through the lesions; and

- use the kissing balloon or kissing stent technique simultaneously.

\section{Unilateral iliac lesion}

In cases of unilateral iliac lesions, several techniques were used, as described below.

When the lesion is less than $2 \mathrm{~cm}$ from the aortic bifurcation, a contralateral puncture is also necessary.

Contralateral puncture may also be useful for angiographic control during the procedure.
Brachial access may also be used in case of occlusions, because the lesion may often be recanalized more easily; and, also, in cases of lesions of the external iliac arteries close to the inguinal ligament when there is not enough space to position the introducer. A pigtail catheter positioned via brachial access may also be used for angiographic control during the procedures. In any case, this access is used only in selected cases of iliac artery angioplasty.

\section{Use of stents}

Stents were used selectively according to indications:

- inadequate result of balloon angioplasty with extensive dissection or limiting flow, or with a pressure gradient greater than $11 \mathrm{mmHg}$;

- occlusions;

- ostial lesions; and

- calcified plaques or large ulcerations.

In ostial or calcified lesions, the balloonexpandable stent was used because of its greater radial force and more accurate release. When the lesion reached the common and external iliac arteries, or when the lesions were very long and in tortuous segments, self-expanding nitinol stents were used because of their marked flexibility.

\section{Figures of cases in the series}

\section{Case 1}

Patient with trophic lesion in fifth toe, stenosis of left common iliac artery and subocclusion of left external iliac artery treated with angioplasty and balloon-expandable stent in left common iliac artery and self-expanding stent in the distal third of the common iliac artery and external iliac artery (Figures 1a-c).
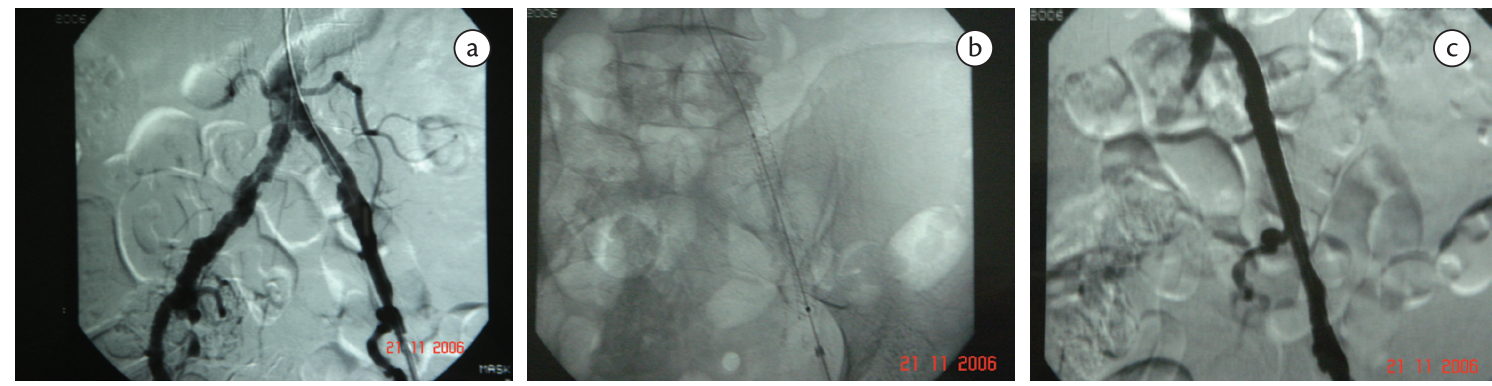

Figure 1. Case 1: (a) arteriogram: stenosis in left common iliac artery and subocclusion in left external iliac artery; (b) expanding balloon stent in common iliac artery and self-expanding balloon in external iliac artery; (c) final angiogram. 


\section{Case 2}

Patient with disabling intermittent claudication and bilateral ostial stenosis of the common iliac artery. Treatment with a balloon-expanding kissing stent (Figures 2a-c).

\section{Case 3}

Patient had undergone stent angioplasty of left common iliac artery four years before and had in-stent restenosis and stenosis of renal artery. A neobifurcation was prepared with kissing stents and stent angioplasty of renal artery (Figures 3a-e).

\section{Case 4}

Patient with trophic lesion of left foot. Aortogram revealed total left common iliac artery occlusion and proximal ulcerated plaque in right common iliac artery. Treatment with balloon-expanding kissing stent (Figures 4a-d).

\section{RESULTS}

Mean patient age was 62 years (minimum: 42; maximum: 89$)$; 37 were male patients $(62.72 \%)$ (Figure 5).

The predominant risk factors were smoking, in $72 \%$ of the cases, and diabetes, in $30 \%$.

The main treatment indications were limiting or disabling intermittent claudication in 30 cases $(50.84 \%)$ and rest pain or trophic lesion (critical ischemia) in 29 cases (49.15\%) (Figure 6).

Lesions were classified as TASC A in 39 cases (66.10\%), TASC B in $13(22.03 \%)$, TASC C in two $(3.38 \%)$ and TASC D in five $(8.47 \%)$ (Figure 7$)$.

Patients had stenosis in the iliac arteries in 42 cases (71.18\% of the cases in the series) and occlusions in 17 cases ( $28.81 \%$ of the cases in the series).

Initial technical success was achieved in 56 cases $(94.91 \%)$. Three were classified as technical failures: two had bilateral lesions, but recanalization of at least one side was achieved (partial technical failure). In one of the patients, with a TASC D lesion, there was no canalization in either side (treatment failure). He died on the 10th postoperative day due to complications of underlying diseases: chronic obstructive pulmonary disease (COPD), diabetes and sepsis.

The patients underwent postoperative follow-up, which included $\mathrm{c}$ ankle-brachial index measurements and a duplex ultrasound scan at 30 days, 3 months, 6 months, 12 months, and every 6 months thereafter. Minimum follow-up was three months, and maximum, 72 months (six years), and mean followup was 22 months. There was a small loss to followup, and it was not possible to calculate late survival.

During postoperative follow-up, there were:

- two occlusions (3.38\%): one patient with occlusion at 12 months after the procedure was asymptomatic and was treated only clinically, without another intervention. Another patient had occlusion 30 days after the procedure and underwent aortobifemoral bypass;

- three restenosis occurred in the first 12 months after angioplasty (5.08\%): two underwent another angioplasty, which was successful, and the other, aortobifemoral bypass because there were severe diffuse lesions of the common and external iliac arteries bilaterally; and

- a major amputation (iliac angioplasty followed by posterior distal femoral tibial bypass. Iliac angioplasty was patent, but the bypass occluded in the first week after operation, and the patient underwent amputation of the thigh).

These data show primary patency in $91.37 \%$ and secondary patency in $94.82 \%$ (Table 1 ).

A patient had more serious complications: perforation of leg artery in a combined infrapopliteal procedure that required postoperative fasciotomy due to compartment syndrome. The patient had chronic renal failure with hemodialysis and had a coagulation disorder, which contributed to the development of
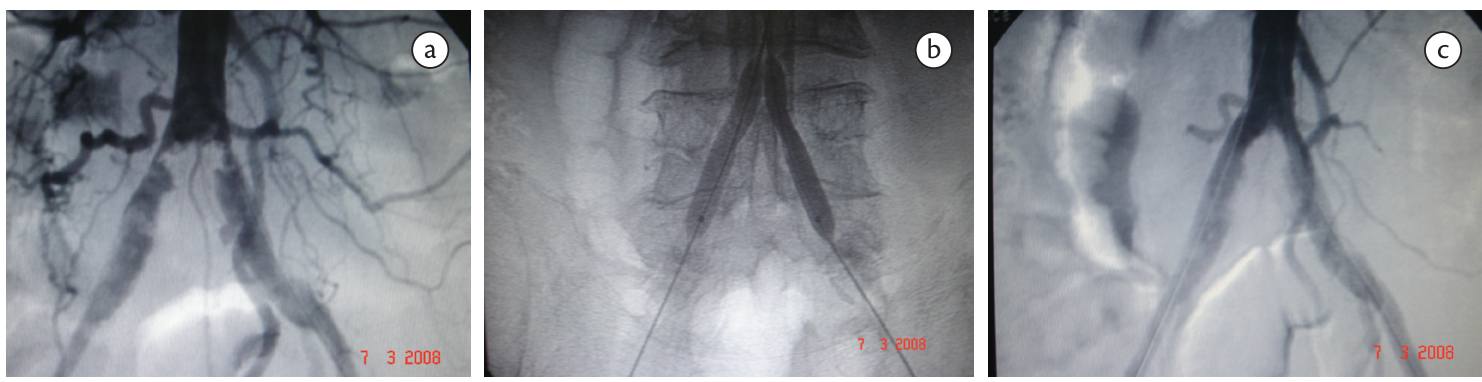

Figure 2. Case 2: (a) angiogram shows bilateral ostial stenosis of common iliac arteries; (b) balloon-expanding kissing stents, $9 \times 39$ $\mathrm{mm}$; (c) final aortogram. 

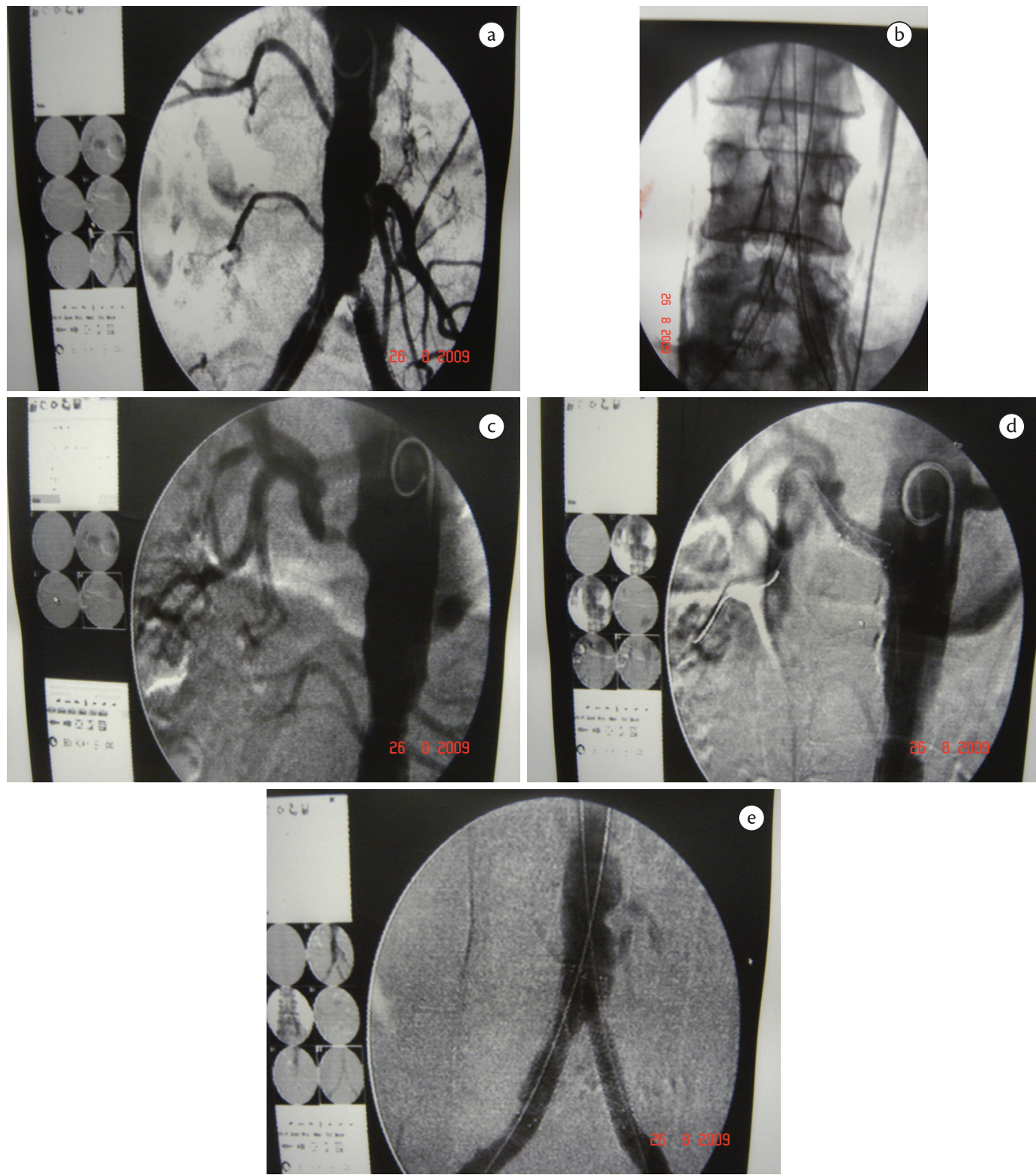

Figure 3. Case 3: (a) intrastent restenosis originating in left common iliac artery; (b) new bifurcation with balloon-expanding kissing stents; (c) severe stenosis in right renal artery; (d) balloon-expanding stent in right renal artery; (e) final aortogram.
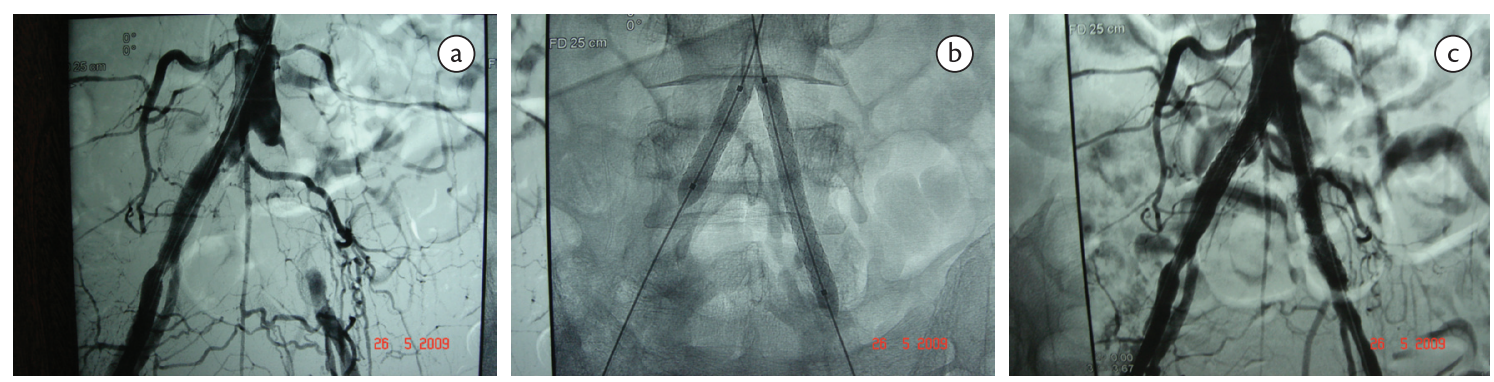

Figure 4. Case 4: (a) arteriogram shows left common iliac artery occlusion and proximal ulcerated plaque in right common iliac artery. (b) balloon-expanding kissing stents, $7 \times 29 \mathrm{~mm}$ in right side and $7 \times 59 \mathrm{~mm}$ in left side; (e) final aortogram. 


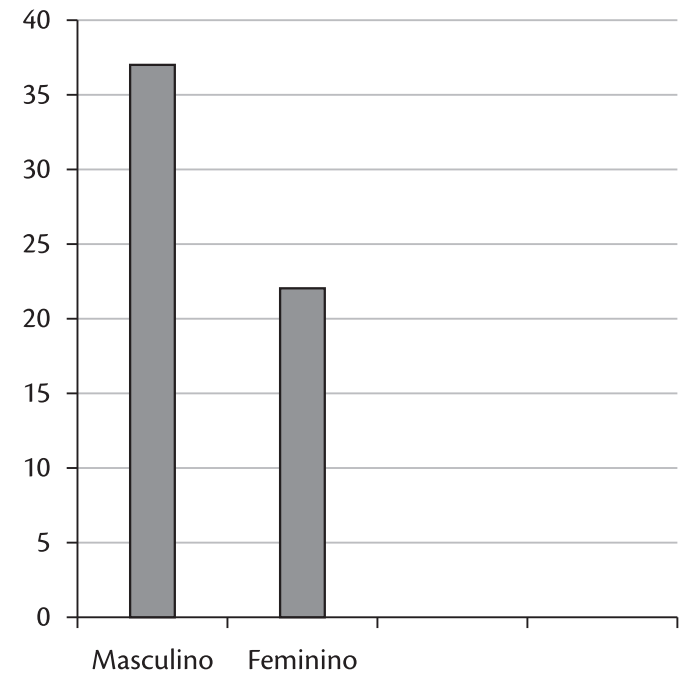

Figure 5. Patient distribution according to sex.

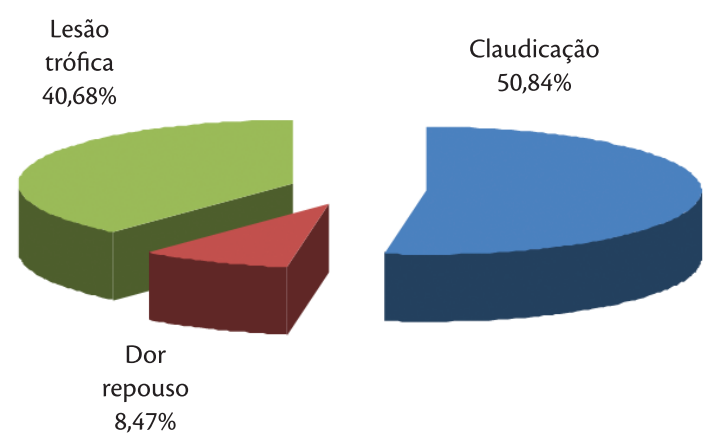

Figure 6. Patient distribution according to degree of ischemia.

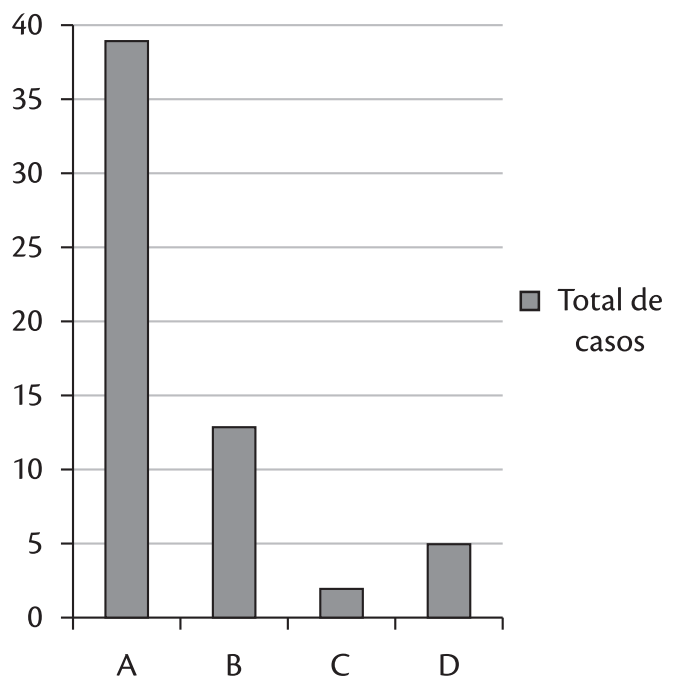

Figure 7. Patient distribution according to TASC classification.

Table 1. Primary and secondary patency rates.

\begin{tabular}{cc}
\hline Patency & Patency rates (\%) \\
\hline Primary & 91.37 \\
Secondary & 94.82 \\
\hline
\end{tabular}

the compartment syndrome and the need to undergo fasciotomy. She recovered satisfactorily.

There were no pseudoaneurysms, retroperitoneal hematoma, arterial occlusions or need of blood transfusion.

There were two deaths in the first 30 days after operation (3.3\% mortality) not associated with the angioplasty. A kidney transplant recipient, who was hospitalized with acute pancreatitis and developed acute ischemia of the right lower limb, required fibrinolysis and angioplasty of the common iliac artery and limb perfusion was restored. Ten days after the procedure, she died due to complications of acute pancreatitis (respiratory failure and sepsis). Another patient, with a TASC D lesion in which recanalization was not achieved, already described above, died due to COPD complications, diabetes and sepsis.

\section{DISCUSSION}

Although open surgery, particularly aortobifemoral bypass, apparently results in better patency in the long term than endovascular surgery in the aortoiliac region, the risks of open surgery are much higher than those of endovascular treatment, not only in terms of mortality, but also in regard to morbidity and patient return to usual daily activities. A meta-analysis of 25 studies about aortobifemoral bypass found $4.4 \%$ deaths and $12.2 \%$ complications, in addition to $91 \%$ patency at five years for patients with claudication and $87 \%$ for those with critical ischemia ${ }^{10}$.

However, studies about the use of an endovascular approach showed that, in a series of 151 cases of angioplasty of the iliac arteries, there were no deaths and only one minor complication (inguinal hematoma), whereas assisted primary and secondary patency was $98 \%$ at seven years. Most lesions treated in this series were stenosis and TASC A or B lesions ${ }^{11}$. Therefore, the approach for each patient should take into consideration general health and type of lesion.

In a retrospective study with 138 patients with iliac occlusions treated with angioplasty and stents, patency rates were $90 \%, 85 \%, 80 \%$ and $68 \%$ at three, five, seven and 10 years. According to the authors, an initial endovascular approach seems to be justifiable for most patients, particularly older patients and those with severe comorbidities, because it is less invasive than surgery ${ }^{12}$. Another retrospective study with 937 patients found $73 \%$ primary patency, $88 \%$ assisted primary patency and $90 \%$ secondary patency at 10 years, with mortality rates lower than 
$1 \%{ }^{13}$. Pedron et al. ${ }^{14}$ studied a series of 24 cases of iliac occlusion treated with angioplasty and found technical success rates of $91.7 \%$ and patency of $71 \%$ at 1 year ${ }^{14}$. Moreira et al..$^{15}$ evaluated neointimal hyperplasia using intravascular ultrasound 8 months after the procedure in 30 patients that underwent angioplasty of the iliac arteries and stenting, and found that it was self-limited and did not lead to significant restenosis in any of the cases ${ }^{15}$.

In our study, most patients had TASC A or B lesions ( $88.13 \%$ of the cases) and stenosis (42 patients, or $71.18 \%$ of the cases), and primary (91\%) and secondary (94\%) patency rates were also high, whereas morbidity and mortality rates were low. These findings suggest that the endovascular approach should be the first treatment alternative in case of stenosis and TASC A and B lesions. If the endovascular treatment fails for a patient, there remains the option of undergoing another angioplasty procedure or attempting open surgery. Of the three patients with restenosis in our series, two underwent another angioplasty and one, open surgery, as shown in the results of postoperative follow-up. Of the two that had occlusion during follow-up, one underwent surgery, and the other was treated only clinically.

Initial technical and clinical success of angioplasty in the treatment of stenosis in iliac arteries is greater than $90 \%$ in practically all publications in the literature. This rate may reach almost $100 \%$ in the case of focal stenosis. In contrast, the success rate in the case of occlusions is about $85 \%$ and depends on fibrinolysis. The development of advanced materials and the availability of more advanced techniques have resulted in greater technical success when recanalizing occlusions ${ }^{16}$.

Several recent studies have also confirmed the efficacy and safety of this method. A study with a series of 118 patients with occlusion of the iliac artery treated with primary stenting found a secondary patency of $93 \%$ at five years of follow-up ${ }^{17}$.

However, the indications of interventions, be them open surgery or endovascular approach, have not changed. In the case of patients with claudication, they should be treated first clinically, with the indication of smoking cessation, walking, control of risk factors, use of antiplatelet drug, vasodilating drugs and statins. Invasive treatments are indicated in the following conditions, according to recommendations of the Brazilian Society of Angiology and Vascular Surgery ${ }^{18}$.

- limiting claudication;
- disabling claudication;

- no improvement with clinical treatment;

- rest pain; and

- trophic lesion.

In the series of patients in this study, these criteria were used to indicate interventions. The decision about invasive treatment for patients with claudication should also be made based on the individual context of each patient. Age, social life, fitness and professional status should be taken into consideration, and the simple application of only a rigid classification system should be avoided. In some specific cases, patients with moderate to severe claudication may become candidates for invasive treatment. Quality of life questionnaires may be used to decide whether or not an invasive procedure should be used and to select patients that will have the greatest benefit from that type of intervention ${ }^{19}$. Angioplasty may improve the quality of life of patients with claudication when compared with clinical treatment and physical exercises alone ${ }^{20}$.

The decision about a selective or routine use of stenting to treat iliac arteries remains controversial ${ }^{21}$. The Dutch Iliac Stent Trial (DIST) conducted a prospective and randomized comparative study of selective and routine stenting of 279 patients with claudication, and found similar results in both groups, without statistically significant differences ${ }^{22}$. However, a meta-analysis comparing six studies with 1,300 patients that underwent angioplasty of the iliac artery without stenting and eight studies with 816 patients that underwent stenting suggested that the use of stents seems to bring immediate success and better long term results ${ }^{23}$. Another study with a series of patients investigated the use of routine stenting in 90 lesions of the external iliac artery in patients with claudication and found that primary and secondary patency rates were $84 \%$ and $93 \%$ at three years of follow-up ${ }^{24}$.

In our sample, we chose to use stenting selectively in the cases of unsatisfactory results of angioplasty, ostial or calcified lesions or presence of ulcerated plaque. Stents were also used routinely in cases of occlusion.

\section{CONCLUSIONS}

According to studies in the literature, angioplasty in iliac arteries is currently accepted as the method of choice for the treatment of lesions in this anatomic site, particularly because of its low morbidity and mortality rates and its good long term results. 
Findings in this study showed that:

- the primary patency rate for angioplasty in the iliac arteries was $91.3 \%$;

- the secondary patency rate for angioplasty in the iliac arteries was $94.82 \%$;

- the rate of mortality in the first 30 days after operation was $3.3 \%$;

- the rates of complications associated with the procedure were low (1 case of arterial perforation); and

- the rate of amputations was low (1 case in the series).

Endovascular treatment is an efficacious, longlasting and safe option for the treatment of peripheral occlusive arterial disease in iliac arteries, particularly TASC A and B lesions with low complication rates and high patency rates, as demonstrated in this study, in which most lesions that underwent treatment received that classification.

Angioplasty in iliac arteries is a low-risk, lowmortality procedures with patency results that compare with those achieved when conventional surgery is used.

\section{REFERENCES}

1. Hallet JW. Comprehensive vascular and endovascular surgery. 2nd ed. Mosby; 2009.

2. Ouriel K. Peripheral arterial disease. Lancet. 2001;358:12571264. http://dx.doi.org/10.1016/S0140-6736(01)06351-6

3. Trans-atlantic Inter-Society Consensus Working Group. Management of pepipheral arterial disease. J Vasc Surg. 2007;45(suppl 5):55-567.

4. Seldinger S. Catheter placement of the needle in percutaneous arteriography: A New Technique. Acta Radiol. 1953;39:368. http:// dx.doi.org/10.3109/00016925309136722

5. Dotter $\mathrm{CT}$, Judkins $M$. Transluminal treatment of arteriosclerotic obstruction. Circulation. 1964;30:654-670. http://dx.doi. org/10.1161/01.CIR.30.5.654

6. Gruntzig A, Hopffh H. Perkutane rekanalisation chronischer arterieller verschlusse mit einem neven dilatationskatheter: modifikation der Dotter-technik. Dtsch Med Wochenschr. 1974;99:2502-2510. http://dx.doi. org/10.1055/s-0028-1108161

7. Palmaz JC, Richter GM, Noldge G, Kauffmann GW, Wenz W. Intraluminal Palmaz stent implantation. The first clinical case report on balloon-expanded vascular prosthesis. Radiology. 1987;27:560-63.

8. Moore WS, Ahn SS. Endovascular surgery. 3rd ed. Philadelphia: WBSaunders Company; 2001.

9. Schneider PA. Endovascular skills: guidewire and catheter skills for endovascular surgery. 3nd ed. Informa heathcare USA; 2009.

10. Vries SO, Hununk MGM. Results of aortic bifurcation grafts for aortoiliac occlusive disease : a meta-analysis. J Vasc Surg. 1997 Oct;26(4):558-59. http://dx.doi.org/10.1016/ S0741-5214(97)70053-3
11. Kudo T, Chandra FA, Ahn S. Long-term uotcomes and predictors of iliac angioplasty with stenting.J Vasc Surg. 2005 Sep;42(3):46675. http://dx.doi.org/10.1016/j.jvs.2005.05.002

12. Gandini R, Fabiano S, Chiocchi M, Chiappa R, Simonetti G. Percutaneous treatment in iliac artery occlusion: long-term results. Cardiovasc Intervent Radiol. 2008 Nov-Dec;31(6):1069-76. http://dx.doi.org/10.1007/s00270-008-9386-5

13. Davies MG, Bismuth J, Saad WE, Naoum JJ, Peden EK, Lumsden $A B$. Outcomes of reintervention for recurrent disease after percutaneous iliac angioplasty and stenting.J Endovasc Ther. 2011 Apr;18(2):169-80. http://dx.doi.org/10.1583/10-3257.1

14. Pedron C, Ristow AV, Cury-Filho JM, Martin HS, Peixoto CC, Fonseca LMB. Tratamento endovascular da oclusão das artérias ilíacas. Radiol Bras. 2001;34(5):261-265. http://dx.doi.org/10.1590/ S0100-39842001000500004

15. Moreira SM, Kambara AM, Ajzen S, Costa Junior JR. Quantificação volumétrica da hiperplasia neointimal em artérias ilíacas após implante de suporte intravascular metálico. Radiol Bras. 2009;42(4):231-234. http://dx.doi.org/10.1590/ S0100-39842009000400008

16. Saket RR, Rzavi MK, Padidar A, Kee ST, Sze DY, Dake MD. Novel intravascular ultrasound-guided method to create transluminal arterial communications: initial experience in peripheral occlusive disease and aortic dissection. J Endovasc Ther. 2004;11(3):274-280. http://dx.doi.org/10.1583/03-1133.1

17. Ozkan U, Oguzkurt L, Tercan F. Technique, complication and long term outcome for endovascular treatment of iliac artery oclusion Cardiovasc Intervent Radiol. 2010 Feb;33(1):18-24. http://dx.doi. org/10.1007/s00270-009-9691-7

18. Sociedade Brasileira de Angiologia e Cirurgia Vascular - SBACV. Diretrizes SBACV. J Vasc Br. 2005;4.

19. Aquarius AE, Denolet J, Hamming JF, Breek JC, De Vries J. Impaired heath status and invasive treatment in peripheral arterial disease: a prospective 1-year follow-up study. J Vasc Surg. 2005;41:436-42. http://dx.doi.org/10.1016/j.jvs.2004.12.041

20. Greenhalgh RM, Belch JJ, Brown LC. The adjuvant benefit of angioplasty in patients with mild to moderate intermitent claudication managed by supervised exercise, smoking cessation advice and best medical therapy: results from two randomised trials for stenotic femoropopliteal and aortoiliac disease. Eur J Vasc Endovasc Surg. 2008 Dec;36(6):680-8. http://dx.doi.org/10.1016/j. ejvs.2008.10.007

21. Casserly IP, Sachar R, Yadav JS. Manual of peripheral vascular intervention. Lippincott Williams e Wilkins; 2005.

22. Tetteroo E, Van der Graaf Y, Bosch JL. Randomised comparison of primary stent placement versus primary angioplasty followed by selective stent placement in patients with iliacartery occlusive disease. Dutch Iliac Stent Trial Study Group. Lancet. 1998;351:1153-1159. http://dx.doi.org/10.1016/ S0140-6736(97)09508-1

23. Bosch JL, Hunink MG. Meta-analysis of the results of percutaneous transluminal angioplasty and stent placement for aorto-iliac occlusive disease. Radiology. 1997;204:87-96.

24. Maurel B, Lancelevee J, Jacobi D, Bleuet F, Martinez R, Lermusiaux P. Endovascular treatment of external iliac artery stenoses for claudication with sistematic stenting. Ann Vasc Surg. 2009 NovDec;23(6):722-8. http://dx.doi.org/10.1016/j.avsg.2008.05.019 
Correspondence Leonardo Ghizoni Bez Rua dos Otoni, 909, sala 2002 - Santa Efigênia CEP 30150-270 - Belo Horizonte (MG), Brazil E-mail: Lgbez@terra.com.br

Author information

${ }^{1}$ LGB is vascular surgeon at Hospital Felício Rocho. ${ }^{2} L G B$ is head of the Service of Vascular Surgery at Hospital do Instituto de Previdência dos Servidores do Estado de Minas Gerais - IPSEMG.

Author contributions Conception and design: LGB Analysis and interpretation: LGB Data collection: LGB Writing the article: $L G B$ Critical revision of the article: $L G B$ Final approval of the article*: LGB Statistical analysis: LGB Overall responsibility: LGB

*All authors should have read and approved of the final version of the article submitted to J Vasc Bras. 


\title{
Annex 1
}

\section{PROTOCOL FOR PERIPHERAL ANGIOPLASTY - DATA COLLECTION}

\author{
IDENTIFICATION (attach tag) \\ Name \\ Sex \\ Registration number \\ Age
}

Description of clinical signs and symptoms

$\square$ Intermittent claudication.

$\square$ Acute occlusion Degree:

Risk factors

distance

$\square$ Disabling claudication
$\square$ Rest pain
$\square$ Tissue lesion

Smoking

$\square$ Diabetes

$\square$ Deep vein thrombosis $\square$ hypertension

$\square$ Other:

Renal failure

$\square$ Hyperlipidemia

Characteristics of trophic lesion

RLL:

LLL:

Pulses

RLL:

LLL:

Doppler ultrasound

Femoral

Dorsalis pedis artery

Popliteal

Posterior tibial artery

Dorsalis pedis

Posterior tibial

Ankle-brachial index

Rutherford

Arteriogram / Angio-CT / Angio-MRI / Duplex (lesion description)

RLL:

LLL:

$\square \mathrm{I}$
$\square \mathrm{II}$
$\square \mathrm{III}$
$\square \mathrm{IV}$
$\square \mathrm{V}$
$\square \mathrm{VI}$

Lesion anatomy

\section{Iliac arteries}

A 1 Stenosis $<3 \mathrm{~cm} \mathrm{CIA} \mathrm{or} \mathrm{EIA} \mathrm{(unilateral} \mathrm{or} \mathrm{bilateral)}$

B 2 Stenosis, single lesion $3-10 \mathrm{~cm}$

B 3 Total stenosis, 2 lesions $<5 \mathrm{~cm}$ in $\mathrm{CIA}$ or EIA

B 4 Unilateral occlusion $\mathrm{CIA}$

C 5 Bilateral stenosis 5-10 cm CIA and/or EIA

C 6 Unilateral occlusion EIA

C 7 Bilateral occlusion CIA

D 8 Multiple, diffuse stenosis in CIA, EIA and CFA

D 9 Unilateral occlusion of $\mathrm{CIA}$ and EIA

D 10 Bilateral occlusion of EIA

D 11 Diffuse disease affecting aorta and both iliac arteries

D 12 lliac stenosis in patient with AAA

Infrapopliteal lesions
Femoral popliteal segment

A 1 Stenosis up to $3 \mathrm{~cm}$, except when origin in SFA or distal popliteal artery

B 2 Stenosis/occlusion, single lesion 3-5 cm not affecting distal popliteal artery

B 3 highly calcified stenosis, up to $3 \mathrm{~cm}$

B 4 Multiple stenosis/occlusions, each lesion $<3 \mathrm{~cm}$

B 5 Single or multiple lesion in the absence of continuous tibial runoff to improve inflow for bypass

C 6 Stenosis/occlusion, single lesion greater than $5 \mathrm{~cm}$

C 7 Multiple stenosis/occlusions $3-5 \mathrm{~cm}$

D 8 Complete occlusion of CFA or SFA or PA or TFT 
A1 Stenosis, single lesion smaller than $1 \mathrm{~cm}$ in tibial or fibular arteries

B2 Multiple focal stenosis, lesions of tibial or fibular arteries, each smaller than $1 \mathrm{~cm}$

B3 One or two lesions, focal stenosis, each smaller than $1 \mathrm{~cm}$ in the tibial trifurcation

B4 Tibial or fibular stenosis associated with femoral popliteal angioplasty

C5 Stenosis, lesion $1-4 \mathrm{~cm}$ long

C6 Occlusions $1-2 \mathrm{~cm}$ long in tibial or fibular artery

C7 Long stenosis, lesion in tibial trifurcation

D8 Occlusions $>2 \mathrm{~cm}$ in tibial or fibular artery

D9 Diffuse disease in tibial or fibular artery

\section{Endovascular approach}

Treatment description:

Date:

\section{Surgical team:}

Segment treated
$\square$ aorta
$\square$ Iliac arteries
$\square$ Femoral artery
$\square$ Popliteal artery
$\square$ Infrapopliteal artery
$\square$ Carotid artery
$\square$ a. subclavian artery

Access:

$\square$ Ipsilateral femoral artery
$\square$ contralateral femoral artery
$\square$ Anterograde femoral
$\square$ R brachial
$\square$ L brachial
$\square$ radial
$\square$ axillary
$\square$ venous
Complications:

Immediate postoperative $A B$ index $(24 \mathrm{~h})$ :

POSTOPERATIVE FOLLOW-UP

1) 30 DAYS

$\mathrm{ABI}$

Imaging findings

2) 3 MONTHS

$\mathrm{ABI}$

Imaging findings

3) 6 MONTHS

$\mathrm{ABI}$

Imaging findings

4) 1 YEAR

$\mathrm{ABI}$

Imaging findings

5) SUBSEQUENT FOLLOW-UP

RECORD ABI AND IMAGING FINDINGS

A)

B)

C)

D) $\square$ Venous graft

Synthetic graft

Arteriovenous fistula

AVM

Renal

mesenteric

$\square$ vein:

Filter of vena cava

1 Pre-dilatation

Balloon:

Post-dilatation

Balloon:

No. of stent

Sizes:

Expanding balloon

$\checkmark$ Self-expanding balloon

surgery time ( $\mathrm{min}$ ) 